\title{
Towards Greener Mechanosynthesis of Functional Calixarenes ${ }^{\dagger}$
}

\author{
Clara Silveiro ${ }^{1}$, Vasco D. B. Bonifácio ${ }^{2, *}$, José V. Prata ${ }^{1,3}$, Alexandra I. Costa $1,3, *$ and Patrícia D. Barata $1,3, *$ \\ 1 Área Departamental de Engenharia Química, Instituto Superior de Engenharia de Lisboa, \\ Instituto Politécnico de Lisboa, R. Conselheiro Emídio Navarro, 1, 1959-007 Lisboa, Portugal; \\ claraps96@gmail.com (C.S.); jvprata@deq.isel.ipl.pt (J.V.P.) \\ 2 iBB-Institute for Bioengineering and Biosciences, Instituto Superior Técnico, Universidade de Lisboa, \\ Av. Rovisco Pais, 1, 1049-001 Lisbon, Portugal \\ 3 Centro de Química-Vila Real, Universidade de Trás-os-Montes e Alto Douro, 5001-801 Vila Real, Portugal \\ * Correspondence: vasco.bonifacio@tecnico.ulisboa.pt (V.D.B.B.); acosta@deq.isel.ipl.pt (A.I.C.); \\ pbarata@deq.isel.ipl.pt (P.D.B.) \\ + Presented at the 24th International Electronic Conference on Synthetic Organic Chemistry, \\ 15 November-15 December 2020, Online; Available online: https://ecsoc-24.sciforum.net/.
}

Citation: Silveiro, C.; Bonifácio, V.D.B.; Prata, J.V.; Costa, A.I.; Barata, P.D. Towards Greener Mechanosynthesis of Functional Calixarenes. Chem.

Proc. 2021, 3, 48. https://doi.org/10.3390/ ecsoc-24-08405

Academic Editors: Julio A. Seijas and M. Pilar Vázquez-Tato

Published: 14 November 2020

Publisher's Note: MDPI stays neutral with regard to jurisdictional claims in published maps and institutional affiliations.

Copyright: ( $\odot 2020$ by the authors. Licensee MDPI, Basel, Switzerland. This article is an open access article distributed under the terms and conditions of the Creative Commons Attribution (CC BY) license (http://creativecommons.org/licenses /by/4.0/).

\begin{abstract}
The awareness of sustainability led to increasing global demand for processes that use lower energy, produce reduced waste, use fewer organic solvents, and offer improved selectivity. In this context, mechanochemistry re-emerged as a powerful green methodology. The conventional synthesis and functionalization of calixarenes, both on the upper and lower rim, has been the subject of numerous studies but only a few were reported using a mechanochemical approach. Herein, we present new mechanically assisted key synthetic steps towards a more sustainable route to calix[4]arenes functionalized in the lower rim.
\end{abstract}

Keywords: calixarenes; mechanochemistry; planetary ball mill; sustainability; green chemistry; Sonogashira-Hagihara coupling

\section{Introduction}

Calixarenes are a well-known class of synthetic macrocycles that possess an intramolecular bow-shaped cavity capable of accommodating different types of molecular guests. Their synthesis, properties, and applications have been extensively reviewed [1,2]. Presenting considerable functional and tuneable diversity, their synthesis and functionalization are still challenging. In recent years, the incorporation of calixarenes into polymeric matrices led to the development of smart materials with interesting sensing properties [3], but calixarenes are expanding in different fields, such as chemotherapeutics [4] and nanosciences [5].

Mechanosynthesis is an emergent green technology that proceeds under solventless conditions, at room temperature, or by heating originated from the grinding process. Thus, this methodology allows waste reduction and lower energy consumption, without compromising or even enhancing chemical transformations. Besides matching all these requirements, another major advantage and an extraordinary feature of mechanosynthesis is the elimination of solubility issues due to the highly energetic elastic, plastic, and shear deformations that lead to chemical reactions. Moreover, mechanochemistry is a truly new synthetic tool, by allowing access to products otherwise found possible only in classical solution reactions. Nevertheless, and despite great achievements made in the last few years [6], the field of mechanosynthesis is still rather unexplored. In particular, synthetic reports of calixarenes prepared by a mechanochemical approach are almost nonexistent [7-10]. Hence, we explored the mechanosynthesis of selected calixarene intermediates, aiming at a greener route for smart calixarene-based materials. 


\section{Materials and Methods}

p-Tert-butylcalix[4]arene (1) was synthesized using a reported protocol [11]. $\mathrm{KOH}$, $\mathrm{K}_{2} \mathrm{CO}_{3}$, 4-iodobenzyl bromide, copper(I) iodide, tetrabutylammonium fluoride hydrate, and nitrobenzene were purchased from Aldrich. 18-Crown-6, cyclohexene, ethynyltrimethylsilane, and palladium(II) acetate were purchased from Fluka. Triphenylphosphine was purchased from Merck and recrystallized from $n$-hexane. Triethylamine was purchased from Riedel-de-Haën and used as received. Unless otherwise stated the reagents were used as received. Analytical thin-layer chromatography (TLC) was performed on Merck Kieselgel 60, F-254 silica-gel, 0.2-mmthick plates. Fourier transform infrared (FTIR) spectra were measured on a Bruker Vertex 70. ${ }^{1} \mathrm{H}$ NMR $(400 \mathrm{MHz})$ and $\mathrm{H}$-decoupled ${ }^{13} \mathrm{C}$ NMR $(100 \mathrm{MHz})$ were recorded on a Bruker ARX 400 spectrometer with $\mathrm{CDCl}_{3}$ as the solvent and tetramethylsilane as the internal standard. The mechanosynthesis was performed on a PM100 Planetary Ball Mill (Retsch) using a $50 \mathrm{~mL}$ stainless-steel or zirconium oxide reactor and 200 stainless-steel or zirconium oxide balls with $5 \mathrm{~mm}$ of diameter.

\subsection{5,27-Bis-(4-vinyl-benzyloxy)-26,28-dihydroxy-p-tert-butylcalix[4]arene (2)}

Calixarene 1 ( $20 \mathrm{mg}, 0.027 \mathrm{mmol}, 1.0$ equiv.), $\mathrm{KOH}(3.787 \mathrm{mg}, 0.0675 \mathrm{mmol}, 2.5$ equiv.), 4-vinylbenzyl chloride ( $9.8 \mu \mathrm{L}, 0.0621 \mathrm{mmol}, 2.3$ equiv.), nitrobenzene $(0.4 \mu \mathrm{L}$, $0.027 \mathrm{mmol}, 1.0$ equiv.) and 18-crown-6 (14.5 $\mu \mathrm{L}, 0.0675 \mathrm{mmol}, 2.5$ equiv.) were added to a $50 \mathrm{~mL}$ zirconium oxide reactor containing 200 zirconium oxide balls. The reactor was then adjusted into the planetary ball mill. The mixture was ground for $60 \mathrm{~h}$, at $500 \mathrm{rpm}$, with rotation inversion cycles of $30 \mathrm{~min}$. (2.5 min. pause between inversion cycles). After this period the reactor was opened and the mixture was analyzed by TLC (dichloromethane/hexane 1:1), which showed a mixture of $\mathbf{1}$ and 2 . The obtained yellowish resin was then dissolved in $50 \mathrm{~mL}$ of dichloromethane and filtered by gravity to remove 18-crown- 6 . After solvent removal to dryness, the yellow residue was dissolved in $50 \mathrm{~mL}$ of $5 \% \mathrm{HCl}$ and extracted with chloroform $(3 \times 50 \mathrm{~mL})$. The organic phases were collected, dried over anhydrous $\mathrm{MgSO}_{4}$, and after solvent removal to dryness the product was dried under vacuum. Calixarene 2 was further recrystallized from chloroform $/ n$ propanol and obtained as an off-white solid in $10 \%$ yield $(2.2 \mathrm{mg})$. FT-IR $(\mathrm{KBr}) v\left(\mathrm{~cm}^{-1}\right)$ : $3430(\mathrm{~s}, \mathrm{OH}) 3150\left(\mathrm{w},=\mathrm{CH}_{2}\right), 1629(\mathrm{~m}, \mathrm{C}=\mathrm{C}), 993,907\left(\mathrm{~m}, \mathrm{H}_{2} \mathrm{C}=\mathrm{CH}\right) ;{ }^{1} \mathrm{H} \mathrm{NMR}\left(\mathrm{CDCl}_{3}\right) \delta$ (ppm): $10.37(\mathrm{~s}, 4 \mathrm{H}, \mathrm{ArO} \underline{\mathrm{H}}), 7.64(4 \mathrm{H}, \mathrm{d}$, vinyl-ArH $J=8.0 \mathrm{~Hz}) 7.40(4 \mathrm{H}, \mathrm{d}, \operatorname{vinyl}-\mathrm{Ar} \underline{\mathrm{H}}, J=$ $8.0 \mathrm{~Hz}), 7.08(\mathrm{~s}, 8 \mathrm{H}, \operatorname{Ar} \underline{\mathrm{H}}), 7.05(4 \mathrm{H}, \mathrm{s}, \operatorname{Ar} \underline{\mathrm{H}}), 6.80(4 \mathrm{H}, \mathrm{s}, \operatorname{Ar} \underline{\mathrm{H}}), 6.77\left(1 \mathrm{H}, \mathrm{dd}, \mathrm{C} \underline{\mathrm{H}}=\mathrm{CH}_{2}, J=\right.$ 10.6 and $17.6 \mathrm{~Hz}), 5.79\left(1 \mathrm{H}, \mathrm{d}, \mathrm{CH}=\mathrm{CH}_{2}, J=17.6 \mathrm{~Hz}\right), 5.27\left(1 \mathrm{H}, \mathrm{d}, \mathrm{CH}=\underline{\mathrm{CH}}_{2}, J=10.6 \mathrm{~Hz}\right), 5.04$ $\left(4 \mathrm{H}, \mathrm{s} \mathrm{ArOC} \underline{\mathrm{H}}_{2} \mathrm{Ar}\right), 4.28\left(\mathrm{dd}, 8 \mathrm{H}, \mathrm{ArC}_{2} \mathrm{Ar}, J=13.4 \mathrm{~Hz}\right), 3.52\left(\mathrm{~d}, 4 \mathrm{H}, \mathrm{ArC}_{2} \mathrm{Ar}, J=13.9 \mathrm{~Hz}\right)$, $3.27\left(4 \mathrm{H}, \mathrm{d}, \mathrm{ArC} \underline{\mathrm{H}}_{2} \mathrm{Ar}, J=13.1 \mathrm{~Hz}\right), 1.27\left(18 \mathrm{H}, \mathrm{s}, \mathrm{C}\left(\mathrm{C}_{3}\right)_{3}\right), 1.24\left(\mathrm{~s}, 36 \mathrm{H}, \mathrm{C}\left(\mathrm{C}_{3}\right)_{3}\right), 0.94(18 \mathrm{H}$, s, $\left.\mathrm{C}\left(\mathrm{CH}_{3}\right)_{3}\right)$.

\subsection{5,11,17,23-Tetrakis(1,1-dimethylethyl)-25,27-bis(4-iodobenzyloxy)-26,28- dihydroxycalix[4]arene (3)}

Calixarene 1 ( $50 \mathrm{mg}, 0.068 \mathrm{mmol}, 1.0$ equiv.), $\mathrm{K}_{2} \mathrm{CO}_{3}$ anhydrous (freshly flared) (35.45 $\mathrm{mg}$, $2.57 \mathrm{mmol}$, 3.8 equiv.), 4-iodobenzyl bromide ( $50.19 \mathrm{mg}, 0.161 \mathrm{mmol}, 2.38$ equiv.) were added to a $50 \mathrm{~mL}$ zirconium oxide reactor containing 200 zirconium oxide balls. The reactor was then adjusted into the planetary ball mill. The mixture was ground for $7 \mathrm{~h}$, at $500 \mathrm{rpm}$, with rotation inversion cycles of $15 \mathrm{~min}$. (5 s pause between inversion cycles). After this period the reactor was opened and the mixture was analyzed by TLC (dichloromethane/petroleum ether 1:1), which showed total consumption of $\mathbf{1}$ and the formation of 3. The obtained brown residue was then dissolved in $50 \mathrm{~mL}$ of dichloromethane and filtered by gravity. After solvent removal to dryness, the light brown residue was extracted with water $(3 \times 50 \mathrm{~mL})$. The organic phases were collected, dried over anhydrous $\mathrm{MgSO}_{4}$, and after solvent removal to dryness the product was dried under vacuum to give a beige solid. Calixarene 3 was further recrystallized from 
chloroform/methanol and obtained as a white solid in $27.2 \%$ yield (19.8 mg). FT-IR (KBr) v ( $\left.\mathrm{cm}^{-1}\right)$ : 3530, 3409 (s, OH), 2961 (s, CH, (CH3)3), 1594 (m, C=C), 1482 (s, CH, CH2), 871, 800 (s, =CH). ${ }^{1} \mathrm{H}$ NMR $\left(\mathrm{CDCl}_{3}\right) \delta(\mathrm{ppm}): 7.72(4 \mathrm{H}, \mathrm{d}, \mathrm{I}-\mathrm{Ar} \underline{\mathrm{H}}, J=7.4 \mathrm{~Hz}), 7.41(4 \mathrm{H}, \mathrm{s}, \mathrm{I}-\mathrm{Ar} \underline{\mathrm{H}})$, $7.10(2 \mathrm{H}, \mathrm{s}, \mathrm{ArO} \underline{\mathrm{H}}), 7.04(4 \mathrm{H}, \mathrm{s}, \mathrm{Ar} \underline{\mathrm{H}}), 6.77(4 \mathrm{H}, \mathrm{s}, \mathrm{I}-\mathrm{Ar} \underline{\mathrm{H}}), 4.99$ (4H, s, $\left.\mathrm{ArOC} \underline{H}_{2} \mathrm{Ar}\right), 4.22$ $\left(4 \mathrm{H}, \mathrm{d}, \mathrm{ArC} \underline{\mathrm{H}}_{2} \mathrm{Ar}, J=13.0 \mathrm{~Hz}\right), 3.27\left(4 \mathrm{H}, \mathrm{d}, \mathrm{ArC} \underline{\mathrm{H}}_{2} \mathrm{Ar}, J=13.0 \mathrm{~Hz}\right), 1.29\left(18 \mathrm{H}, \mathrm{s}, \mathrm{C}\left(\mathrm{C}_{3}\right)_{3}\right)$, $0.93\left(18 \mathrm{H}, \mathrm{s}, \mathrm{C}\left(\mathrm{C}_{3}\right) 3\right)$.

\subsection{5,11,17,23-Tetrakis(1,1-dimethylethyl)-25,27-bis[4-(trimethylsilylethynyl)benzyloxy]-26,28- dihydroxycalix[4]arene (4)}

Calixarene 3 (200 mg, 0.185 mmol, 1.0 equiv.), Et $3 \mathrm{~N}(740 \mu \mathrm{L}, 4 \mathrm{~mL} / \mathrm{mmol}), \mathrm{Pd}(\mathrm{AcO})_{2}$ (2.077 mg, $9.25 \mu \mathrm{mol}, 5 \mathrm{~mol} \%)$, CuI (3.5 mg, $18.5 \mu \mathrm{mol}, 10 \mathrm{~mol} \%)$, $\mathrm{PPh}_{3}$ (recrystallized from n-hexane) (4.85 mg, $18.5 \mu \mathrm{mol}, 10 \mathrm{~mol} \%$ ), ethinyltrimethylsilane (62 $\mu \mathrm{L}, 0.44 \mathrm{mmol}, 2.4$ equiv.), $\mathrm{MgSO}_{4}$ anhydrous ( $1 \mathrm{~g}, 5$ equiv./mg, reaction milling auxiliary), and cyclohexene $(40 \mu \mathrm{L}, 0.2 \mu \mathrm{L} / \mathrm{mg}$, catalyst milling auxiliary) were added to a $50 \mathrm{~mL}$ zirconium oxide reactor containing 200 zirconium oxide balls. The reactor was then adjusted into the planetary ball mill. The mixture was ground for $8 \mathrm{~h}$, at $500 \mathrm{rpm}$, with rotation inversion cycles of $30 \mathrm{~min}$. (2.5 min. pause between inversion cycles). After this period the reactor was opened and the mixture was analyzed by TLC (dichloromethane/hexane 1:4, double elution), which showed a mixture of 3 and 4 . The obtained light brown residue was then dissolved in $50 \mathrm{~mL}$ of dichloromethane and filtered by gravity to remove $\mathrm{MgSO}_{4}$. After solvent removal to dryness, the mixture was redissolved in $50 \mathrm{~mL}$ of dichloromethane and extracted with a saturated $\mathrm{NH}_{4} \mathrm{Cl}$ solution $(2 \times 50 \mathrm{~mL})$ and water. The organic phases were collected, dried over anhydrous $\mathrm{MgSO}_{4}$, and after solvent removal to dryness the product was dried under vacuum. Calixarene 4 was further recrystallized from dichloromethane/methanol and obtained as a light brown solid in $36.9 \%$ yield $(69.7 \mathrm{mg})$. FT-IR $(\mathrm{KBr}) v\left(\mathrm{~cm}^{-1}\right):$ 3528, 3427, $3412(\mathrm{~s}, \mathrm{OH}), 2960$ (s, CH, $\left.\left(\mathrm{CH}_{3}\right) 3\right), 2158(\mathrm{C} \equiv \mathrm{C})$, 1605, 1592 (m, $\mathrm{C}=\mathrm{C}), 1485$ (s, $\left.\mathrm{CH}, \mathrm{CH}_{2}\right), 1250$ (s, $\left.\mathrm{Si}\left(\mathrm{CH}_{3}\right)_{3}\right), 872,867,806$ (s, =CH). ${ }^{1} \mathrm{H} \mathrm{NMR}\left(\mathrm{CDCl}_{3}\right) \delta(\mathrm{ppm})$ : $7.72(\mathrm{~d}, 4 \mathrm{H}, \mathrm{I}-\mathrm{Ar} \underline{\mathrm{H}}, J=8.3 \mathrm{~Hz}), 7.49$ (s, 8H, (CH3) $3 \mathrm{SiC} \equiv \mathrm{C}-\mathrm{Ar} \underline{\mathrm{H}}), 7.41(\mathrm{~d}, 4 \mathrm{H}, \mathrm{I}-\mathrm{Ar} \underline{\mathrm{H}}, J=8.1$ $\mathrm{Hz}), 7.10$ (d, 4H, $\mathrm{ArOH}), 7.04(\mathrm{~d}, 8 \mathrm{H}, \mathrm{ArH}), 6.77$ (s, 4H, I-Arg $), 6.75$ (s, 4H, ArH $), 5.01$ (s, $\left.4 \mathrm{H}, \mathrm{ArOC} \underline{H}_{2} \mathrm{Ar}\right), 4.99$ (s, 4H, $\left.\mathrm{ArOC}_{2} \mathrm{Ar}\right), 4.20$ (dd, 8H, $\left.\mathrm{ArC}_{2} \underline{\mathrm{Ar}}_{1} J=13.1 \mathrm{~Hz}\right), 3.23$ (dd, $\left.8 \mathrm{H}, \mathrm{ArC} \underline{\mathrm{H}}_{2} \mathrm{Ar}, J=13.1 \mathrm{~Hz}\right), 1.28\left(\mathrm{~d}, 36 \mathrm{H}, \mathrm{C}\left(\underline{\mathrm{CH}}_{3}\right)_{3}\right), 0.94\left(\mathrm{~s}, 36 \mathrm{H}, \mathrm{C}\left(\mathrm{C}_{3}\right)_{3}\right), 0.27(\mathrm{~s}, 18 \mathrm{H}$, $\left.\mathrm{Si}\left(\mathrm{C}_{3}\right)_{3}\right)$.

\subsection{5,11,17,23-Tetrakis(1,1-dimethylethyl)-25,27-bis(4-ethynylbenzyloxy)-26,28- dihydroxycalix[4]arene (5)}

Calixarene 4 (20 mg, 0.19 mmol, 1.0 equiv.) and n-Bu4NF (11.492 mg, 0.043 mmol, 2.1 equiv.) were added to a $50 \mathrm{~mL}$ zirconium oxide reactor containing 200 zirconium oxide balls. The reactor was then adjusted into the planetary ball mill. The mixture was ground for $1 \mathrm{~h}$, at $500 \mathrm{rpm}$, with rotation inversion cycles of $15 \mathrm{~min}$. (5 s pause between inversion cycles). After this period the reactor was opened and the mixture was analyzed by TLC (dichloromethane/hexane 3:1), which showed a total consumption of 4 and the formation of 5. The obtained white residue was then dissolved in $25 \mathrm{~mL}$ of dichloromethane and washed with a solution of $10 \% \mathrm{HCl}(25 \mathrm{~mL})$ and water. The organic phases were collected, dried over anhydrous $\mathrm{MgSO}_{4}$, and after solvent removal to dryness the product was dried under vacuum. Calixarene 5 was further recrystallized from dichloromethane/methanol and obtained as a foamy brown-orange solid in 58.2\% yield $(10 \mathrm{mg})$. FT-IR $(\mathrm{KBr}) v\left(\mathrm{~cm}^{-1}\right)$ :

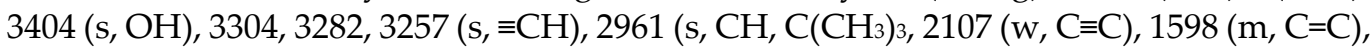

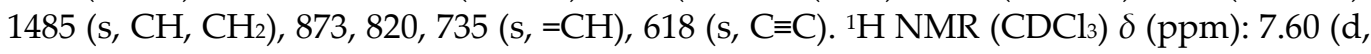
$4 \mathrm{H}, \mathrm{C} \equiv \mathrm{C}-\mathrm{Ar} \underline{\mathrm{H}}, J=8.0 \mathrm{~Hz}), 7.52(\mathrm{~d}, 4 \mathrm{H}, \mathrm{C} \equiv \mathrm{C}-\mathrm{Ar} \underline{\mathrm{H}}, J=8.0 \mathrm{~Hz}), 7.12(\mathrm{~s}, 2 \mathrm{H}, \mathrm{ArO} \underline{\mathrm{H}}), 7.04(\mathrm{~s}$, $4 \mathrm{H}, \mathrm{Ar} \underline{\mathrm{H}}), 6.77$ (s, 4H, $\mathrm{Ar} \underline{\mathrm{H}}), 5.04$ (s, 4H, $\left.\mathrm{ArOC} \underline{\mathrm{H}}_{2} \mathrm{Ar}\right), 4.24$ (d, 4H, $\mathrm{ArC}_{2} \underline{\mathrm{Ar}}_{2} \mathrm{~J}=13.0 \mathrm{~Hz}$ ), $3.27\left(\mathrm{~d}, 4 \mathrm{H}, \mathrm{ArC}_{2} \mathrm{Ar}, J=13.0 \mathrm{~Hz}\right), 3.11(\mathrm{~s}, 2 \mathrm{H}, \equiv \mathrm{C} \underline{\mathrm{H}}), 1.29\left(\mathrm{~s}, 18 \mathrm{H}, \mathrm{C}\left(\underline{\mathrm{CH}}_{3}\right) 3\right), 0.93(\mathrm{~s}, 18 \mathrm{H}$, $\left.\mathrm{C}\left(\mathrm{CH}_{3}\right)_{3}\right)$. 


\section{Results and Discussion}

The green synthesis of functional calix[4]arenes was performed using a mechanochemical approach. Overall, the solventless synthetic route showed important advantages over conventional protocols. In this work, starting from $p$-tert-butylcalix[4]arene 1, two functional calixarenes monomers, bearing aryl vinyl or aryl ethynyl pending units, were successfully prepared (Scheme 1).
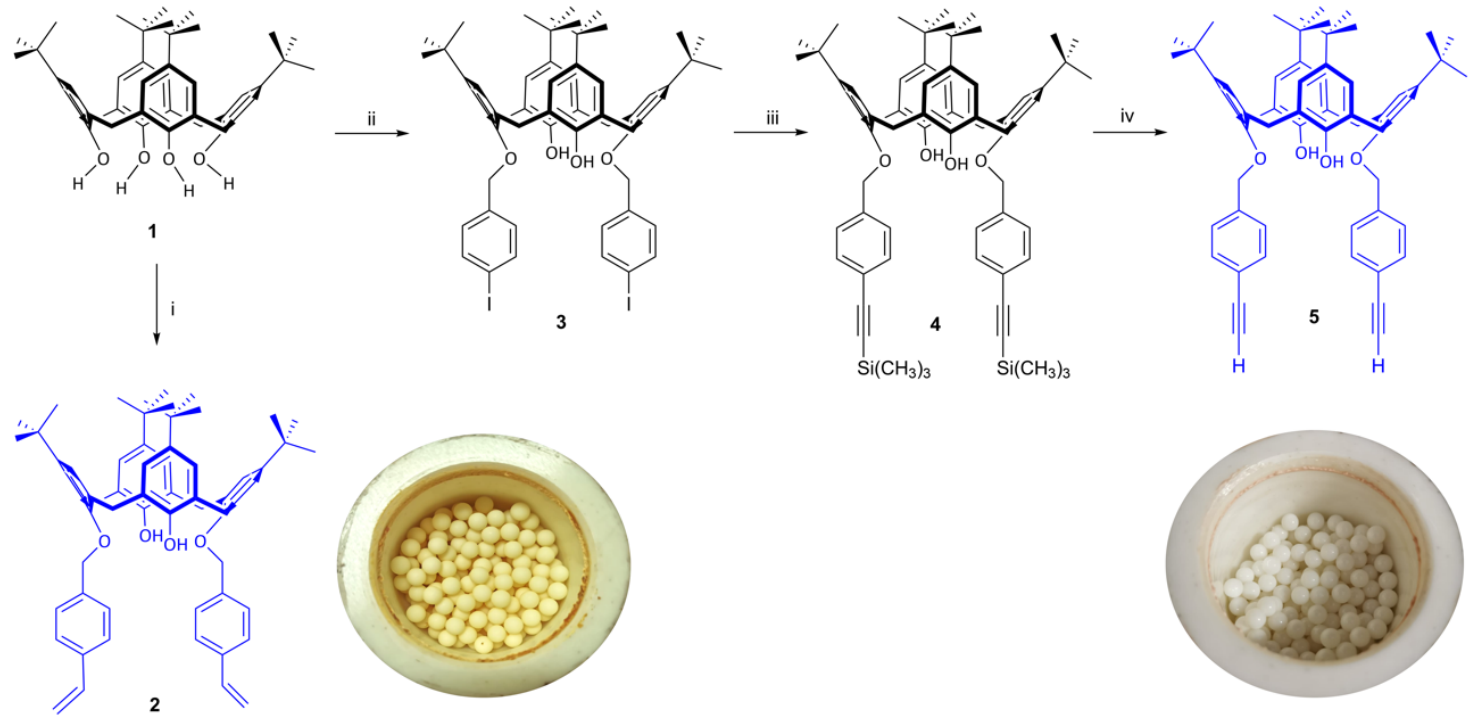

Scheme 1. Mechanosynthesis of functional calix[4]arenes: (i) calixarene $\mathbf{1}$ (1.0 equiv.), $\mathrm{KOH}$ (2.5 equiv.), 4-vinylbenzyl chloride (2.3 equiv.), nitrobenzene (1.0 equiv.), 18-crown-6 (2.5 equiv.), $500 \mathrm{rpm}, 60 \mathrm{~h}$; (ii) calixarene 1 (1.0 equiv.), $\mathrm{K}_{2} \mathrm{CO}_{3}$ anhydrous (3.8 equiv.), 4-iodobenzyl bromide (2.38 equiv.), $500 \mathrm{rpm}, 7 \mathrm{~h}$; (iii) calixarene 3 (1.0 equiv.), Et3 N (4 mL/mmol), $\mathrm{Pd}(\mathrm{AcO})_{2}(5 \mathrm{~mol} \%), \mathrm{CuI}(10 \mathrm{~mol} \%), \mathrm{PPh}_{3}(10 \mathrm{~mol} \%)$, ethynyltrimethylsilane (2.4 equiv.), $\mathrm{MgSO}_{4}$ anhydrous (5 equiv./mg), cyclohexene $(0.2 \mu \mathrm{L} / \mathrm{mg}), 500 \mathrm{rpm}, 8 \mathrm{~h}$; (iv) calixarene 4 (1.0 equiv.), $n$-Bu4NF (2.1 equiv.), $500 \mathrm{rpm}, 1 \mathrm{~h}$. The photos show crude mixtures of calixarenes $\mathbf{2}$ and $\mathbf{5}$ at the end of the reaction.

The reactions were conducted in a planetary ball mill using both stainless-steel and zirconium oxide reactors, and the reactor was found to influence the reaction outcome. In most cases, a low yield or no reaction was observed when the stainless-steel was used.

Calixarene 2 [12] was synthesized in one step using 4-vinylbenzyl chloride, $\mathrm{KOH}$ as a base, and nitrobenzene as a milling auxiliary (equimolar amount). It is well known that $\mathrm{K}^{+}$ions can be easily trapped in the calixarene cavity, altering the cone configuration, and ultimately decreasing the lower rim reactivity. Therefore, the effect of the addition of 18crown-6, a ligand with an affinity for potassium cations, was investigated. Although a lower yield was observed in comparison with the optimized conventional protocol, $10 \%$ vs. $48 \%$ yield, the reaction time was reduced from $168 \mathrm{~h}$ (reflux in acetonitrile) to $60 \mathrm{~h}$ (milling at $500 \mathrm{rpm}$ ) (Table 1).

Table 1. Comparison between conventional and mechanochemical-assisted synthesis of functional calix[4]arenes.

\begin{tabular}{cccccc}
\hline \multirow{2}{*}{ Calixarene } & \multicolumn{3}{c}{ Conventional Synthesis } & \multicolumn{2}{c}{ Mechanosynthesis } \\
\cline { 2 - 6 } & Yield (\%) & Time (h) & Solvent & Yield (\%) & Time (h) \\
\hline $\mathbf{2}$ & 48.0 & 168 & $\mathrm{ACN}^{1}$ & 10.0 & 60 \\
$\mathbf{3}$ & 81.1 & 24 & $\mathrm{ACN}^{1}$ & 27.2 & 7 \\
$\mathbf{4}$ & 36.9 & 24 & $\mathrm{THF}^{1}$ & 68.1 & 8 \\
$\mathbf{5}$ & 49.1 & 0.5 & $\mathrm{THF}^{2}$ & 58.2 & 0.25 \\
\hline
\end{tabular}

${ }^{1}$ Refluxing conditions. ${ }^{2}$ Reaction at room temperature. $\mathrm{ACN}=$ acetonitrile, $\mathrm{THF}=$ tetrahydrofuran. 
Further reaction optimization to increase the reaction yield is undergoing. Surprisingly, the base selection was also found to be critical. When $\mathrm{K}_{2} \mathrm{CO}_{3}$ (conventional route base) was used, only traces of calixarene 2 were obtained.

Similarly, calixarene 5 [13] was prepared in three steps (Table 1). First, calixarene 1 was reacted with 4-iodobenzyl bromide using $\mathrm{K}_{2} \mathrm{CO}_{3}$ anhydrous as a base to give calixarene 3 after $7 \mathrm{~h}$ of milling at $500 \mathrm{rpm}$. The yield is much lower than the conventional reaction, $27.2 \%$ vs. $81.1 \%$ yield; however, the reaction time was reduced from 24 to $7 \mathrm{~h}$ under solventless conditions. Next calixarene 4 was obtained from calixarene 3 via a Sonogashira-Hagihara coupling in $8 \mathrm{~h}$ of milling at $500 \mathrm{rpm}$. The reaction yield was optimized by the introduction of $\mathrm{MgSO}_{4}$ anhydrous as a grinding auxiliary and cyclohexene as an additive. Olefins, and 1,5-cyclooctadiene (COD) in particular, have been reported to remarkably accelerate palladium-catalyzed cross-coupling solid-state reactions by acting as efficient molecular dispersants [14]. In this protocol, we chose cyclohexene, a much cheaper and less toxic olefin. Under these conditions, calixarene 4 was obtained in $36.9 \%$ yield after $8 \mathrm{~h}$ of grinding, which is quite good if compared with conventional conditions $(68.1 \%)$, using tetrahydrofuran under reflux for $24 \mathrm{~h}$. Finally, calixarene 5 was obtained in $15 \mathrm{~min}$. by removal of the TMS protecting group using $n$-Bu4NF. The mechanochemicalassisted deprotection, in this case, was even higher than that obtained under conventional conditions (58.2\% vs. $49.1 \%$ yield), avoiding the use of tetrahydrofuran.

\section{Conclusions}

In summary, we present, for the first time, the preparation of key calix[4]arenes monomers, precursors of important calixarene-based polymers, by a mechanochemical-assisted protocol. Four calixarenes were synthesized in low to moderate yields (10-58\%, after recrystallization), in much faster reaction times under solventless conditions. However, we anticipate that is still room for reaction optimization, namely exploring different bases, grinding auxiliaries, catalytic systems, and reaction times. Overall, mechanochemistry is foreseen as a novel, effective, and green strategy for the preparation of advanced calixarenes.

Author Contributions: Conceptualization, J.V.P., P.D.B., A.I.C., and V.D.B.B.; methodology, P.D.B. and A.I.C.; formal analysis, P.D.B. and A.I.C.; investigation, C.S.; resources, P.D.B., A.I.C., and V.D.B.B.; data curation, C.S.; writing - original draft preparation, V.D.B.B.; writing - review and editing, P.D.B., A.I.C., and V.D.B.B.; supervision, P.D.B., A.I.C., and V.D.B.B.; funding acquisition, J.V.P., P.D.B., A.I.C., and V.D.B.B. All authors have read and agreed to the published version of the manuscript.

Funding: This research was funded by Fundação para a Ciência e a Tecnologia (FC\&T, Portugal) thought projects PTDC/MEC-ONC/29327/2017, UIDB/00616/2020 and UIDP/00616/2020.

Institutional Review Board Statement: Not applicable.

Informed Consent Statement: Not applicable.

Conflicts of Interest: The authors declare no conflict of interest.

\section{References}

1. Asfari, Z.; Böhmer, V.; Harrowfield, J. Calixarenes 2001; Vicens, J., Ed.; Kluwer Academic Publishers: Dordrecht, The Netherlands, 2001.

2. Español, E.S.; Villamil, M.M. Calixarenes: Generalities and their role in improving the solubility, biocompatibility, stability, bioavailability, detection, and transport of biomolecules. Biomolecules 2019, 9, 90.

3. Kumar, R.; Sharma, A.; Singh, H.; Suating, P.; Kim, H.S.; Sunwoo, K.; Shim, I.; Gibb, B.C.; Kim, J.S. Revisiting fluorescent calixarenes: From molecular sensors to smart materials. Chem. Rev. 2019, 119, 9657-9721.

4. Yousaf, A.; Hamid, S.A., Bunnori, N.M.; Ishola, A.A. Applications of calixarenes in cancer chemotherapy: Facts and perspectives. Drug Des. Dev. Ther. 2015, 9, 2831-2838.

5. Guérineau, V.; Rollet, M.; Viel, S.; Lepoittevin, B.; Costa, L.; Saint-Aguet, P.; Laurent, R.; Roger, P.; Gigmes, D.; Martini, C.; et al. The synthesis and characterization of giant calixarenes. Nat. Commun. 2019, 10, 113. 
6. James, S.L.; Adams, C.J.; Bolm, C.; Braga, D.; Collier, P.; Friščić, T., Grepioni, F.; Harris, K.D.; Hyett, G.; Jones, W.; et al. Mechanochemistry: Opportunities for new and cleaner synthesis. Chem. Soc. Rev. 2012, 41, 413-447.

7. Atwood, J.L.; Hardie, M.J.; Raston, C.L.; Sandoval, C.A. Convergent synthesis of p-benzylcalix[7]arene: Condensation and UHIG of $p$-benzylcalix[6 or 8]arenes. Org. Lett. 1999, 1, 1523-1526.

8. Roberts, B.A.; Cave, G.W.V.; Raston, C.L.; Scott, J.L. Solvent-free synthesis of calix[4]resorcinarenes. Green Chem. 2001, 3, 280284 .

9. Abbasi, S.; Naghipoor, A. One pot mechanochemical synthesis of resorcinol based calix[4]arene and it's ab initio study. Asian J. Chem. 2009, 21, 4943-4946.

10. Antesberger, J.; Cave, G.W.V.; Ferrarelli, M.C.; Heaven, M.W.; Raston, C.L.; Atwood, J.L. Solvent-free, direct synthesis of supramolecular nano-capsules. Chem. Commun. 2005, 892-894.

11. Gutsche, C.D.; Iqbal, M. p-tert-Butylcalix[4]arene. Org. Synth. 1990, 68, 234.

12. Mendes, A.R.; Gregório, C.C.; Barata, P.D.; Costa, A.I.; Prata, J.V. Linear and crosslinked copolymers of $p$-tert-butylcalix[4]arene derivatives and styrene: New synthetic approaches to polymer-bound calix[4]arenes. React. Funct. Polym. 2005, 65, 9-21.

13. Costa, A.I.; Prata, J.V. Synthesis and Rh(I)-catalyzed polymerization of 1,3-diphenylyne-calix[4]arene compounds: Novel conjugated, calixarene-based polymers. Polym. Sci. Part A Polym. Chem. 2006, 44, 7054-7070.

14. Kubota, K.; Seo, T.; Koide, K.; Hasegawa, Y.; Ito, H. Olefin-accelerated solid-state C-N cross-coupling reactions using mechanochemistry. Nat. Commun. 2019, 10, 111. 